\title{
Seguimiento de Jesús en el Espíritu, fundamento de una reforma eclesial ${ }^{*}$
}

\author{
Víctor Codina, S.J., \\ profesor emérito de la \\ Universidad Católica Boliviana de Cochabamba
}

\section{Aproximación histórica}

Siguiendo a Congar ${ }^{1}$, quisiera destacar algunos elementos de la historia de la Iglesia que nos ayuden a enfocar correctamente el tema de la reforma eclesial hoy.

\subsection{Iglesia primitiva}

En primer lugar, llama la atención que en la Iglesia primitiva, en la época de los padres de la Iglesia y hasta la alta Edad Media, no se hable de reforma de la Iglesia, sino de la reforma moral y espiritual de los cristianos. Se habla de renovar la vida bautismal de los fieles (2 Cor 3, 18; Col 3, 10), de no conformarse a este mundo ( $\mathrm{Rm} \mathrm{12,2;} \mathrm{Ef} \mathrm{4,23).} \mathrm{Se} \mathrm{trata} \mathrm{de} \mathrm{recuperar} \mathrm{la} \mathrm{imagen} \mathrm{divina} \mathrm{recibida}$ en la creación $(\mathrm{Gn} 1,26)$ y, según la antropología oriental, pasar de la imagen a la semejanza divina. Y todo ello en Cristo, a cuya imagen hemos sido creados.

Inocencio V (1276), más tarde, resumirá así todo el proceso de reconfiguración de la imagen divina: el hombre formado por la creación, deformado por el pecado, reformado por la gracia, informado por la doctrina, conformado por asimilación a Cristo, transformado por la contemplación, es finalmente deiformado por la gloria ${ }^{2}$.

Este artículo fue presentado en el Simposio Teológico del Cono Sur, organizado por Amerindia en noviembre de 2014, bajo el lema Ecclcesia semper reformanda.

1. Y. M. Congar, "Reforma"; en P. Poupard (ed.), Diccionario de las religiones, Herder, Barcelona, 1987, pp. 1486-1491.

2. Ibid. p. 1487. Los siguientes datos históricos también se apoyan en Congar. 
Los Padres de la Iglesia hablan de la Iglesia santa y pecadora, de la casta meretrix $x^{3}$, del trigo y la cizaña presentes en la Iglesia, pero no se pronuncian por lo que hoy día se llama reforma o cambio estructural en la Iglesia ${ }^{4}$.

\subsection{Iglesia del segundo milenio}

La idea de la reforma de las instituciones eclesiales empieza en el segundo milenio con referencia a la vida monástica y canónica, para ajustarse a la Ecclesiae primitivae forma. La vida monástica pasa por diferentes reformas: Benito de Aniane, Cluny, Cister, entre otros, y es la que ha mantenido presente en la Iglesia la idea de reforma; reforma que en el monacato primitivo ya estaba presente como alternativa a la Iglesia constantiniana.

No es casual que Hildebrando, un monje de Cluny, futuro Gregorio VII, haga la llamada reforma gregoriana para defender la libertas Ecclesiae frente a príncipes seculares, aunque su costo haya sido una recentralización eclesial romana que ha durado hasta el Vaticano II.

Papas y concilios medievales posteriores comenzarán a hablar de que la Iglesia siempre necesita reforma (Alejandro III, 1179), de la necesidad de una reforma in capite et in membris (con ocasión del Concilio de Vienne, 1311). En estos casos la reforma se dirige principalmente a los abusos de los clérigos, "reforma de sandalias y capuchas", como ironizará Lutero.

Pero junto a estas reformas desde arriba de la Iglesia, se suceden del siglo XI al XIII una serie de movimientos proféticos de laicos que desde la base desean una vuelta al Evangelio y a la Iglesia primitiva: cátaros, valdenses, albigenses, humillados, pobres de Dios, el milenarismo de Joaquín de Fiore, los mendicantes, sobre todo, franciscanos y dominicos. Es conocido el llamado del Señor a Francisco a reparar la Iglesia, que solo más tarde el mismo Francisco comprenderá que no se trataba únicamente de restaurar la paredes viejas de San Damián de Asís.

Pero será sobre todo Lutero quien encabezará el movimiento moderno de la Reforma de la Iglesia, simbolizado en las tesis sobre las indulgencias en 1517. No es reforma solo de costumbres, sino de puntos de doctrina tradicional para volver a la Escritura. La Reforma se considera Ecclesia reformata, semper reformanda. Frente a la Reforma, Trento será un concilio pro reformatione, que iniciará la llamada Contrarreforma católica.

3. H. U. von Baltasar, “Casta meretrix”, en Sponsa Verbi, I, Cristiandad, Madrid, 1966, pp. 239-366.

4. K. Rahner, Cambio estructural en la Iglesia, Cristiandad, Madrid, 1973; y C. Schickendantz, Cambio estructural en la Iglesia, EDUCC, Córdoba, 2005. 
Podemos preguntarnos por el impacto reformador eclesial de la Devotio moderna, de los Hermanos de la vida común de Windesheim y en especial de $L a$ imitación de Cristo, de Tomás de Kempis (1380-1471), que insisten en una piedad cristocéntrica y en una devoción popular - pero muy antiintelectual-, moral y subjetivista. También podemos preguntarnos por el efecto reformador eclesial de los Ejercicios espirituales de Ignacio de Loyola (1491-1556), que se centran en la búsqueda personal de la voluntad divina siguiendo la vida de Jesús, pero que no inciden directamente en la reforma eclesial: la referencia eclesial se limita a las reglas para sentir en la Iglesia militante a "nuestra santa madre Iglesia jerárquica", seguramente como reacción frente al movimiento reformador protestante.

\subsection{La reforma del Vaticano II}

Finalmente, el Vaticano II (1962-1965) fue un concilio reformador, una vuelta a las fuentes de la vida cristiana (Palabra, padres, liturgia...) y el deseo de dialogar con el mundo moderno. Este doble movimiento se resumió en dos palabras clave: ressourcement y aggiornamento. Son conocidos los textos que tratan de volver al Cristo llamado a evangelizar a los pobres ( $L G$ 8), de discernir los signos de los tiempos $(G S 4 ; 11 ; 44)$ y de reforma en la Iglesia $(U R 4 ; 6)$. Pero no podemos olvidar que el Vaticano II fue precedido por una serie de movimientos teológicos y eclesiales (bíblico, patrístico, litúrgico, ecuménico, social, pastoral...), que, a pesar de haber sufrido las críticas del magisterio de Pío XII (Humani generis, 1950), fecundaron el terreno para la puesta en marcha del concilio por Juan XXIII y luego por Pablo VI ${ }^{5}$.

La recepción del Vaticano II supuso una reforma de la Iglesia, una verdadera primavera eclesial, pero que duró pocos años (¿hasta 1968?). La presión de movimientos integristas, como el liderado por Mauricio Lefêvbre, y ciertos abusos y exageraciones en la aplicación del concilio produjeron el miedo a divisiones y cismas eclesiales, y en consecuencia el freno del concilio y el surgimiento de una verdadera contrarreforma conciliar.

Todo comenzó ya con Pablo VI cuando mandó introducir la Nota previa en la Lumen gentium, que debilitaba la colegialidad episcopal reafirmando las posturas del Vaticano I. La publicación de las encíclicas Sacerdotalis caelibatus (1967) y Humanae vitae sobre el control de natalidad (1968), sin contar con el apoyo de la colegialidad episcopal, marcan un claro retroceso en la dinámica sinodal. Pablo VI acabó afirmando con mucha angustia que la sombra del Maligno había entrado en la Iglesia ${ }^{6}$.

5. V. Codina, "Hace 50 años hubo un concilio", Cuadernos de Cristianismo y Justicia, n. ${ }^{\circ} 182,2012$.

6. J. Martínez Gordo, "La conversión del papado (Francisco)", Vida Nueva, n. ${ }^{\circ}$ 2908, 13-19 de septiembre de 2014, pp. 23-30. 
Esta postura, que se define como hermenéutica de la continuidad frente a la hermenéutica de la reforma, se consolida en los pontificados de Juan Pablo II y Benedicto XVI. No es que estos papas no pensasen en grande. Juan Pablo II tuvo un gran dinamismo geopolítico, pero mantenía inalterada la doctrina, mientras que Benedicto XVI se centraba en el plano filosófico, pero dejaba que la Iglesia se cerrase a toda innovación. Es el llamado invierno eclesial. El papa Francisco, como luego veremos, retoma el impulso reformador del Vaticano II.

Desde América Latina hay que afirmar que, desde Medellín (1968), se produce una recepción creativa del concilio a partir de la lectura de los signos de los tiempos desde un mundo marcado por la pobreza y la injusticia. Fue una verdadera reforma de la Iglesia latinoamericana, una eclesiogénesis pneumática desde la opción por los pobres: laicos comprometidos por la justicia en la sociedad y en la Iglesia, comunidades eclesiales de base, obispos verdaderos santos padres de la Iglesia de los pobres, vida religiosa inserta en medios pobres y populares, surgimiento de una reflexión teológica original, teología de la liberación, etc.

Esta reforma latinoamericana sufrió el impacto de la contrarreforma eclesial bajo Juan Pablo II y el cardenal Ratzinger ${ }^{7}$ y sufrió la violencia de las dictaduras y sectores oligárquicos: fue una reforma regada con la sangre martirial de obispos como Romero y Angelleli, de teólogos como Ellacuría, de sacerdotes, religiosas y religiosos como los Palotinos, Espinal, Alice Dumont, Rutilio Grande... de innumerables laicos, hombres, mujeres y niños, de campesinos, sindicalistas, indígenas y pobres del pueblo. Toda reforma eclesial tiene un gran costo humano.

\section{Aproximación teológica}

\subsection{Para una verdadera reforma}

Congar, que ya antes del concilio publicó un libro sobre verdaderas y falsas reformas de la Iglesia ${ }^{8}$, resume en cuatro puntos las condiciones para una verdadera reforma eclesial: (1) Primacía de la caridad y de la pastoral frente a una postura teórica, ideológica y abstracta. No querer hacer otra Iglesia, sino hacer que la Iglesia sea otra, que se renueve la única Iglesia de Jesús. (2) Mantener la comunión con el conjunto eclesial, con el centro y la periferia, con la urbis y el orbis, no actuar en solitario, sino como parte de la Iglesia, agere ut pars. (3) Tener paciencia, evitar apremios y acciones violentas, pero no vacilar en lo ya decidido ni exasperar a los que padecen las urgencias de los cambios. Se requiere

7. Como expresó J. L. Segundo en su Respuesta al cardenal Ratzinger, Madrid, 1985, el ataque vaticano a la teología de la liberación era en el fondo un ataque al mismo Vaticano II.

8. Y. M. Congar, Verdaderas y falsas reformas en la Iglesia, Instituto de Estudios Políticos, Madrid, 1973 (el original francés es de 1950). 
tiempo y sabiduría para hacer avanzar la reforma. (4) Una verdadera renovación para llegar a la tradición profunda y no introducir novedad de forma mecánica. Una vuelta a las fuentes, a lo originario y fundacional.

De estos puntos quisiera desarrollar sobre todo el último, ya que es el fundamento de todos los demás. ¿Cómo concretar esta vuelta a las fuentes, este ressourcement?

\subsection{El seguimiento de Jesús}

Jon Sobrino expresa con su lucidez acostumbrada el fundamento de toda verdadera reforma: "Siempre que la Iglesia ha pasado por momentos de crisis, relajación o desorientación, los cristianos más lúcidos han vuelto al seguimiento de Jesús - como lo hizo evidentemente D. Bonhoeffer - para encontrar orientación e identidad, relevancia y gozo en la vida cristiana".

Esto supone volver a la Palabra, volver al Evangelio, volver a Jesús el Cristo, al Cristo que es Jesús de Nazaret. El seguimiento de Jesús no solo es la fórmula más breve de la fe cristiana, sino la forma más radical de recuperar lo concreto de Jesús, la norma normans, tal como aparece en los Evangelios que son una narrativa del seguimiento.

Evidentemente esto presupone un encuentro personal con el Señor, como expresó Benedicto XVI en Dios es amor (1), y Aparecida recoge (13): "No se comienza a ser cristiano por una decisión ética o una gran idea, sino por el encuentro con un acontecimiento, con una Persona que da un nuevo horizonte a la vida y con ello una orientación definitiva".

Aparecida insiste en ofrecer a todos nuestros fieles un "encuentro personal con Jesucristo" (226 a), y Francisco, al comienzo de Evangelii gaudium, invita "a cada cristiano, en cualquier lugar y situación en que se encuentre, a renovar ahora mismo su encuentro personal con Jesucristo (EG 3).

Este encuentro con Jesús, como sucedió a los primeros discípulos (Mc 1, 17; 2,14 ; Jn 1, 35-51), es el que conduce luego al seguimiento de Jesús, a las renuncias radicales sobre familia y bienes (Mt 8, 21; Lc 9, 59s; 14, 24-35; Mc 10, 21; Mt 19, 10-12...). "Sígueme" fue la primera y última palabra de Jesús a Pedro ${ }^{10}$. Este seguimiento, luego de la Pascua, se dirige a todos los cristianos. Todo bautizado está llamado a ser discípulo y misionero de Jesús (Mt 28, 19-20).

9. J. Sobrino, "Seguimiento de Jesús"; en C. Floristán y J. J. Tamayo (eds.), Conceptos fundamentales del cristianismo, Trotta, Madrid, 1993, p. 1290.

10. D. Bonhoeffer, El precio de la gracia, Sígueme, Salamanca, 1986; citado ibid., p. 1296 , nota 10 . 


\subsection{Características del seguimiento de Jesús}

Este seguimiento tiene al menos estas tres características. (1) No es un seguimiento intimista e individualista, sino que por ser algo realmente personal incluye la dimensión corporativa: es un seguimiento en comunidad, en grupo, en Iglesia, sinodal, con una perspectiva humana social e incluso cósmica, se abre al pueblo de Dios, al Reino. Seguramente a algunos movimientos reformistas medievales y modernos les faltó la dimensión de comunión eclesial con la urbe y el orbe. (2) Es un seguimiento histórico, del Jesús histórico de Nazaret que vivió entre nosotros y de una Iglesia que está encarnada en el mundo de la historia. No es una simple imitación mimética y externa de Jesús, sino un actuar como Jesús actuó, pero en la historia de hoy, es un seguimiento historizado y actualizado del proyecto de Jesús que es el Reino de Dios. Es un seguimiento que lleva al conocimiento vital de Jesús, a asumir sus opciones por los pobres, los pecadores y los que sufren, su estilo nazareno, su relación con el Padre, su conflicto con el antirreino, su muerte y resurrección. Es un seguimiento que lleva a la praxis y desde la praxis profundiza sobre quién es Jesús.

Podemos retomar la cuestión de por qué movimientos espirituales como la Devotio moderna o los Ejercicios ignacianos, e incluso movimientos espirituales más modernos, no parecen orientarse a la reforma eclesial. La Iglesia, por estar encarnada en la historia, por ser humana y divina ( $L G 8$; $S C$ 2), participa de la fragilidad y el pecado, es santa y pecadora, necesitada de continua conversión; pero además, por ser histórica, debe responder a los desafíos de cada momento para cumplir su tarea evangelizadora. Y todo ello de forma corporativa, comunitaria, también institucional y estructural. A algunos movimientos espirituales medievales y modernos, aunque positivos en cuanto apuntan a la conversión y al discernimiento personal, les falta la dimensión histórica de la imitación y del seguimiento de Jesús.

Dicho de otro modo, el Espíritu de Jesús exige no solo una conversión personal, sino histórica, comunitaria y estructural, en una Iglesia que camina como comunidad histórica hacia el Reino. Por tanto, el seguimiento debe ser historizado y visibilizado en la Iglesia y en la sociedad de hoy. Ni Cristo ni la Iglesia se pueden comprender al margen o por encima de la historia. Si al Cristo de la fe pertenece la historia de Jesús, la historia de la Iglesia pertenece a la eclesiología. Tanto cristología como eclesiología se han de historizar, pues de lo contrario llevarían a un seguimiento intimista, ahistórico y a una eclesiología idealista, triunfalista e irrelevante ${ }^{11}$.

(3) Es un seguimiento en el Espíritu, pues solo desde el Espíritu se puede afirmar que Jesús es el Señor (1 Cor 12, 3), desde el Espíritu se comprende que

11. J. Sobrino, Resurrección de la verdadera Iglesia, Sal Terrae, Santander, 1981, p. 179. 
Jesús es el ungido por el Espíritu, el Mesías, el Cristo, el Hijo enviado por el Padre para anunciar la buena nueva a los pobres, dar vista a los ciegos y libertad a los cautivos (Lc 4, 14-21).

Por otra parte, solo en el Espíritu y desde el Espíritu es posible superar el riesgo de un moralismo ético, de un legalismo esclavizante en el seguimiento. El seguimiento en el Espíritu es sinergia, comunión vital, es configuración existencial y mística con el Señor, el Espíritu es luz, calor, fuerza y suavidad. Y actúa desde abajo, desde los pobres, desde el de profundis de la historia.

Corrientes liberadoras latinoamericanas, al no tener suficientemente presente al Espíritu en su teoría y en su praxis, al acentuar unilateralmente al Jesús histórico, viviendo un cierto cristomonismo práctico, tuvieron el riesgo de degenerar en activismo militante, ideología y frustración.

\subsection{Dimensión trinitaria}

Estas tres dimensiones del seguimiento - comunitario, histórico y pneumático- se interrelacionan pericoréticamente. El Espíritu de Jesús es el que prolonga y realiza la misión y el proyecto de Jesús en la historia, y esto a través de la comunidad de Jesús que es la Iglesia, Iglesia que camina hacia el Reino. El Espíritu que engendró a Jesús de Nazaret de María virgen es el que le guió durante toda su vida, el que le resucitó de entre los muertos, el que fue dado en la Pascua a los discípulos, el que en Pentecostés desciende sobra toda la Iglesia y la humanidad y guía la historia hacia el Reino y su consumación escatológica.

Si nos remontamos a la teología trinitaria, el Filioque (que el Espíritu procede del Padre y del Hijo) puede conducir a una cierta marginación del Espíritu en la vida cristiana, a una acentuación unilateral de lo visible, jerárquico e institucional de la Iglesia. Por esto debe ser complementado con el Spirituque (que el Hijo es engendrado por el Padre y el Espíritu). Las dos manos del Padre, en formulación de Ireneo, deben estar presentes en la vida y acción cristiana. El orden clásico Padre-Hijo-Espíritu se ha de complementar con el también orden tradicional de Padre-Espíritu-Hijo. Y todo ello se ha de vivir en una profunda comunión e interrelación pericorética de amor.

Hoy, en nuestro contexto histórico y eclesial, el seguimiento de Jesús en el Espíritu es el que fundamenta una reforma eclesial, un cambio estructural en la Iglesia de hoy. Este seguimiento del Jesús histórico en una Iglesia y en una sociedad histórica implica, pues, una verdadera pneumatología que ayude a superar el riesgo de cristomonismo. Solo el seguimiento histórico del Jesús histórico en una Iglesia y en una sociedad histórica que esté animado y acompañado por el Espíritu, podrá llevar a cabo una verdadera reforma de la Iglesia. Ni un espiritualismo intimista al margen del Jesús histórico de Nazaret ni un seguimiento de Jesús de Nazaret al margen del Espíritu conducirá a una verdadera reforma eclesial. 


\section{Aproximación al momento eclesial de hoy}

\subsection{La nueva eclesialidad de Francisco}

El papa Francisco ha abierto las puertas y ventanas de la Iglesia al viento del Espíritu y prolonga la reforma del Vaticano II. En su corto pontificado se pueden ya apreciar cambios eclesiales. (1) De una Iglesia poderosa, distante, fría, acartonada, miedosa, reaccionaria, de la cual la gente se aleja y se va... a una Iglesia pobre, sencilla, cercana, acogedora, sincera, realista, que promueve la cultura del encuentro y la ternura. El nuevo obispo de Roma, Francisco, se reconoce pecador y pide oraciones; recuerda que la Iglesia necesita una conversión y una continua reforma evangélica, una reforma a lo Francisco de Asís. (2) De una Iglesia moralista obsesionada por el aborto, el control de la natalidad, el matrimonio homosexual... a una Iglesia que va a lo esencial, que se centra en Jesucristo contemplado y adorado, recupera el Evangelio, anuncia la gran buena noticia de la salvación en Cristo, pues Jesús es lo único que atrae; quiere difundir el olor del Evangelio de Jesús. No puede ser un cristianismo de meras devociones sin Jesús. La alegría del Evangelio llena el corazón de todos los que se encuentran con Jesús.

(3) De una Iglesia centrada en el pecado y que ha hecho una tortura del sacramento de la confesión y ha convertido la petición de sacramentos en una aduana inquisitorial... a una Iglesia de la misericordia de Dios, de la ternura, de la compasión, con entrañas maternales, que refleje la misericordia del Padre, una Iglesia ante todo hospital de campaña que cure heridas de emergencia, que cuide la creación, una Iglesia en la que los sacramentos son para todos, no solo para los perfectos. (4) De una Iglesia centrada en ella misma, autorreferencial, preocupada por el proselitismo... a una Iglesia de los pobres preocupada ante todo del dolor y del sufrimiento humano, de la guerra, del hambre, del paro juvenil, de los ancianos, donde los últimos sean los primeros, donde no se pueda servir a Dios y al dinero; una Iglesia profética, libre ante los poderes de este mundo; en la Evangelii gaudium (53-60) se afirma que el actual sistema económico basado en la idolatría del dinero es injusto, pues enriquece a unos pocos y convierte a una gran mayoría en masas sobrantes, es un sistema excluyente que mata; por esto, lanza un "no" a una economía de exclusión, un "no" a la nueva idolatría del dinero, un "no" al dinero que gobierna en lugar de servir, un "no" a la inequidad que genera violencia.

(5) De una Iglesia encerrada en sí misma, reliquia del pasado, con tendencia a mirarse el ombligo, con sabor a invernadero, que espera que vengan los otros... a una Iglesia que sale a la calle, "callejea la fe", va a los márgenes sociales y existenciales, a las fronteras, a los que están lejos, aun con riesgo de tener accidentes; no teme ser una Iglesia minoritaria y pequeña, con tal que sea semilla y levadura, que abra caminos nuevos, que vaya sin miedo a servir, una Iglesia a la intemperie, que sale a las cunetas del mundo, una Iglesia en estado de misión. (6) 
De una Iglesia que discrimina a los que piensan diferente, a los diversos, a los otros... a una Iglesia que respeta a los que siguen su propia conciencia, a las otras religiones, a los ateos, a los homosexuales, dialoga con no creyentes, con judíos, nuestros hermanos mayores, una Iglesia de puertas abiertas, atenta a los nuevos signos de los tiempos.

(7) De una Iglesia con tendencia restauracionista y de vuelta atrás, que añora el pasado... a una Iglesia que considera que el Vaticano II es irreversible, que hay que implementar sus intuiciones sobre la colegialidad, evitar el centralismo y el autoritarismo en el gobierno, caminar en medio de las diferencias. El papa reconoce que no tiene la respuesta a todas las cuestiones, que hay que reformar el papado, que hay que dar responsabilidad a los laicos, ofrecer más protagonismo a la mujer, desclericalizar a la Iglesia, pues el clericalismo no es cristiano. (8) De una Iglesia con pastores encerrados en sus parroquias, clérigos de despacho, que buscan hacer carrera... a pastores que huelan a oveja, que caminen delante, detrás y en medio del pueblo; el carrerismo es la lepra del papado, la curia es vaticanocéntrica y fácilmente traslada su visión al mundo.

(9) De una Iglesia envejecida, triste, a una Iglesia joven y alegre, levadura y fermento en la sociedad, con la alegría y la libertad del Espíritu, con luz y transparencia, sin nada que ocultar. (10) De una Iglesia ONG piadosa, clerical, machista, monolítica, narcisista... a una Iglesia casa y pueblo de Dios, mesa más que estrado, que respete la diversidad, donde jueguen un papel relevante los laicos, las mujeres, las familias ${ }^{12}$. Vuelve a renacer una primavera eclesial. Pero el papa y la Iglesia de hoy se encuentran frente a cuestiones pendientes.

\subsection{Reformas pendientes}

Hay temas que el concilio no pudo tratar o que no logró desarrollar adecuadamente. Enumeremos una larga lista de los principales: (a) reforma del ministerio petrino, conforme al deseo de Juan Pablo II en su encíclica Ut unum sint (95-96), para que el ejercicio actual del papado deje de constituir el mayor obstáculo para la unión de los cristianos; que el papa deje de ser Jefe de Estado, que haya profunda reforma de la curia que ha sido el mayor freno para el desarrollo del concilio y se interpone entre el papa y los obispos; revisar la cuestión del poder en la Iglesia, aunque se llame "poder sagrado". (b) Revisión de la estructura de nuncios-obispos diplomáticos y de los cardenales que responden a la Iglesia de cristiandad y no a la del Vaticano II. (c) Participación del pueblo cristiano en la elección de sus obispos. (d) Hacer efectiva la colegialidad episcopal con una mayor autonomía de las iglesias locales en temas de doctrina de la fe, derecho, moral y liturgia, y que los sínodos de Roma sean deliberativos y no meramente consultivos. No solo sub Petro, sino cum Petro. (e) Mejorar las relaciones entre

12. V. Codina, "Un año del papa Francisco", Cuarto intermedio, n. ${ }^{\circ}$ 106, 2014, pp. 64-75. 
la Congregación para la Doctrina de la Fe y los teólogos, en un clima de diálogo sincero, respetando los derechos humanos, sin procesos secretos y humillantes que van contra la dignidad humana. (f) Abrirse a otras formas de ministerio ordenado que puede incluir la ordenación de hombres casados, maduros en la fe (viri probati) y que se deje de considerar el celibato como una condición obligatoria para el ministerio latino. (g) Revisión del papel de la mujer en la Iglesia, superando toda forma de patriarcalismo machista y andrócentrico; dentro de esto se debería repensar si la prohibición al ministerio ordenado de la mujer, que se considera como algo "definitivo", es realmente intocable, ya que esta exclusión no tiene fundamento bíblico ni tradicional. (h) Promoción del laicado, de su formación y de sus ministerios, dándoles plena confianza y autonomía, escuchándoles y asesorándose de ellos en temas de su competencia, como pueden ser matrimonio y familia, economía, política, ciencia, cultura, etc. (i) Mayor respeto a los carismas de la vida religiosa, también de la vida religiosa femenina y de los hermanos, sin manipular la vida religiosa clerical para suplir la falta de clero, ni "parroquializarla" indistintamente. (j) Profunda revisión de la doctrina oficial sobre la sexualidad, control de la natalidad y anticonceptivos; deben repensarse seriamente desde la antropología, psicología y ciencia moderna, homosexualidad, relaciones prematrimoniales, comunión de divorciados vueltos a casar, lo mismo que muchos temas de bioética que necesitan un mayor diálogo con la medicina y la genética. (k) Relanzamiento del ecumenismo hoy frenado y una mayor apertura para el diálogo interreligioso. (l) Proseguir la reforma litúrgica, dando más espacio al pluralismo de formas, según culturas y tradiciones y concediendo más libertad a las conferencias episcopales. (m) Renovación del lenguaje eclesial, tanto el teológico y catequético como el del magisterio y de la liturgia, que resulta algo "anacrónico, aburrido, repetitivo, moralizante e inadaptado al tiempo de hoy" (H. Boulad). (n) Finalmente, pero no lo último, la Iglesia del postconcilio ha de tomar muy en serio la propuesta inicial de Juan XXIII de que la Iglesia, ciertamente universal, debe ser ante todo la Iglesia de los pobres ${ }^{13}$.

Hay además temas nuevos, como los movimientos eclesiales de laicos, las nuevas tecnologías, la ecología y el cambio climático, y sobre todo el cambio axial religioso que supera el paradigma religioso del neolítico centrado en el sacerdote, el templo y el sacrificio.

Esta reforma de la Iglesia no es algo puramente intraeclesial y autorreferencial, no es una simple cosmética exterior, cambiar algo para que nada cambie. Se trata de vivir en fidelidad al Evangelio que exige que la Iglesia sea luz y sacramento visible de salvación y creíble para la humanidad. La reforma no termina en la Iglesia, sino en la transformación de la humanidad en la dirección del Reino.

13. V. Codina, "Hace 50 años hubo un concilio", op. cit., pp. 26-27; y "Pedro, de otro modo", Alternativas (20), n. . 46, julio-diciembre 2013. 
En este sentido, los gozos, esperanzas, angustias y tristezas del mundo lo son también de la Iglesia ( $G S$ 1). Nada humano es ajeno a la Iglesia: violencia, sufrimiento, deshumanización, hambre, paro, machismo, paro laboral, inmigración, trata de personas...

Pero también es necesaria una reforma estructural de la Iglesia porque la estructura actual de poder eclesial concentrado en pocas manos y no compartido produce víctimas en el seno eclesial: laicos, mujeres, matrimonios, indígenas, pobres, homosexuales, teólogos, sacerdotes e incluso obispos que sufren la opresiva estructura eclesial dominante. No se puede exigir a la sociedad el cumplimiento de los derechos humanos cuando estos son violados muchas veces sistemáticamente en la institución eclesial.

\subsection{Responsabilidad eclesial}

Ante este cúmulo de problemas que sobrepasan las posibilidades de un solo hombre y de la misma colegialidad episcopal, se puede generar en los fieles una actitud pasiva y de espera de que todo cambio venga desde arriba.

Podríamos retomar aquí el consejo de Congar de tener paciencia y prudencia en las reformas. Pero de cara al pueblo de Dios se pueden promover algunas actitudes concretas: (a) interés por conocer la situación eclesial y la necesidad de reformas. (b) Participar activamente, en cuanto se pueda y según la situación personal, en los procesos de cambio, dando a conocer el propio parecer, sabiendo que todos los cristianos tenemos la unción del Espíritu, que el sensus fidelium, en comunión eclesial, es infalible ( $L G 12)$ y que es importante la opinión pública en la Iglesia. La $L G 37$ cita a Pío XII: "En las batallas decisivas, a veces las iniciativas más afortunadas provienen del frente"14; el mismo Pío XII afirmó que faltaría algo a la vida eclesial si no hubiera opinión pública en la Iglesia, sea por culpa de los pastores o de los fieles ${ }^{15}$; Francisco, en la Evangelii gaudium (119), también insiste en la importancia del instinto de la fe los creyentes, que tienen connaturalidad con las cosas divinas y sabiduría para captarlas intuitivamente. Y (c) para ello, es necesario un discernimiento comunitario, aplicando a temas de la Iglesia lo que la Octogesima adveniens (4) dice sobre la necesidad de discernimientos comunitarios para las opciones políticas de los fieles. Tanto las comunidades de base como otros grupos eclesiales pueden ser el espacio para estos discernimientos comunitarios ${ }^{16}$.

Pero todo esto presupone que toda la Iglesia, desde el papa hasta los cristianos más alejados, entremos en la dinámica del seguimiento de Jesús en el Espíritu, un

14. AAS 42 (1950), 256.

15. Pío XII al Congreso de la prensa católica internacional, 17.02.1950. Cita en Selecciones de Teología, n. 212, 2014, p. 245.

16. Cf. J. A. Pagola, Grupos de Jesús, PPC, Madrid, 2014. 
seguimiento comunitario e histórico, fuera del cual no es posible una verdadera reforma de la Iglesia. Hemos de recuperar la actitud de los cristianos del primer milenio, renovarnos en Cristo, pero siguiendo las enseñazas del segundo milenio, desentrañar las consecuencias comunitarias, estructurales e históricas del seguimiento de Jesús, de modo que dejándonos llevar por el Espíritu colaboremos a que la Iglesia sea realmente un signo evangélico, un sacramento transparente de filiación divina y de fraternidad universal humana. Y todo ello en comunión eclesial.

El Espíritu creador que hizo surgir vida en medio del caos original (Gn 1, 2), el Espíritu que da vida a los huesos muertos (Ez 37), el Espíritu que hizo nacer la Iglesia de Jesús en Pentecostés (Hch 2) es también capaz de renovar hoy la Iglesia.

Acabemos con una invocación epiclética: ¡Ven, Espíritu Santo, y renueva la faz de la tierra y también la faz de la Iglesia de hoy! 